\title{
Os Registros Médicos no I.A.P.B. e o Anteprojeto para seu Arquivo Médico
}

\author{
Adriano Taunay Leite Guimarães
}

A má organização dos registros médicos da Delegacia do D.F. do Instituto de Aposentadoria e Pensões dos Bancários tem constituído motivo permanente, em muitos anos de preocupações administrativas, para acalorados debates entre diretores, médicos, assistentes sociais, enfermeiros, funcionárics em geral, e até mesmo em meio ao pessoal subalterno.

Objetivando melhorar essa situação, organizaram-se Comissões e tomou-se uma série de medidas que, na maioria das vêzes, acarretaram apenas prejuízos, sacrifícios de tempo e de trabalho, pelas discussões intermináveis, que não conduziam a resultados palpáveis.

A experiência tem demonstrado que a falta de sistemática neste campo, ou seja, a falta de planejamento dos registros, de maneira a que possam servir às suas finalidades, bem como a inexistência de lugar apropriado para sua centralização, trazem, primàriamente, demora nos atendimentos, com efeitos secundários inevitáveis: reclamações por parte dos associados, e ausência de coordenação entre os médicos em suas atividades.

O descaso pela centralização implica, ainda, em assistências médicas dispersas, geradoras de sobrecargas de trabalho e de despesas duplicadas ou triplicadas, desnecessàriamente, pela pluralidade de exames onerosos.

A constituição de um Fichário Médico Central, além de eliminar os males apontados, permitiria o recrutamento de pessoal especializado, evitando-se que o trabalho fôsse entregue a pessoal não categorizado, sem treinamento específico para a função.

É preciso assinalar, ainda, que a defesa social, econômica e legal de uma organização de previdência e assistência depende, em grande parte, dos seus registros médicos, que constituem, por isto mesmo, assunto de importância vital. Não é um mero problema de economia interna dessas organizações: é problema que interessa também a uma parte ponderável dessa classe média brasileira, que só agora começa delinear-se no horizonte social.

O Dr. MALColm MaC EACHERN, professor de administração Hospitalar da Northwestern University, dos Estados Unidos, em tese (1) apresentada ao

(1) Malcolm Mac Eachern, Registros Médicos do Hospital, in Anais do I Congresso Interamericano de Medicina, Seção de Assistência e Organização Hospitalar, páginas $721 / 732$. 
I Congresso Interamericano, realizado no Rio de Janeiro, e do qual tivemos a honra de participar, não só ressalta o lugar relevante que têm os registros médicos no campo da pesquisa médica, mas também esclarece seu conteúdo e estabelece medidas eficazes para sua consecução, organização, preservação e utilização.

Cremos que se torna oportuna a transcrição dessa tese: a leitura de alguns de seus tópicos servirá para estabelecer, em definitivo, o papel dos registros médicos, como instrumento administrativo, paralelamente à elucidação de alguns de seus aspectos de organização. $O$ ponto de evolução a que chegou a administração hospitalar do país indica que a ocasião é propícia para debate e exame do problema; o volume e a importância dos créditos orçamentários e extraorçamentários empregados pelo Ministério da Saúde e instituições de previdência social não aconselha apenas êsse debate e exame: exige-o.

\section{I - VALOR DE REGISTRO MÉDICO}

O registro médico tem valores bem conhecidos - serve ao paciente durante a sua doença e, mais tarde, quando êle adoecer novamente; serve ao hospital e ao corpo médico, tanto como indivíduos como em grupos; tem um lugar definido no campo da pesquisa médica.

a) Valor para o paciente:

$\left.1^{\circ}\right)$ Um estudo e exame da doença do paciente fica disponível, em todos os seus detalhes, quando registrado, desde que é impossível a qualquer individuo manter êsses detalhes em seu cérebro.

$2 .^{\circ}$ ) Caso o paciente adoeça em outra ocasião, o registro pode tornar desnecessária a repetição de muitos exames feitos, prèviamente, e informaçăo valiosa fica imediatamente disponível.

3. ${ }^{\circ}$ Economizam-se despesas e tempo do paciente, sendo que o tempo muitas vêzes pode vir a ser o fator decisivo entre a morte e a vida.

b) Valor para o Hospital:

$1 .^{\circ)}$ Os registros médicos são registros originais nos quais tôdas as providências médicas se baseiam. Com êles, o hospital pode fazer uma análise da qualidade e da quantidade do trabalho feito.

$2 .^{\circ}$ ) Os registros fornecem prova definida do resultado exato produzido e suas razões.

c) Para o Médico:

$1^{\circ}$ ) Reconhece-se hoje o valor do registro médico na educação do estudante médico.

$2 .^{\circ}$ ) E importante na educação do médico formado que estuda os sucessos e os fracassos de um certo tratamento no hospital.

d) Em defesa legal:

$11^{\circ}$ ) Na maioria dos casos de processos por erros, tanto- o médico comø - hospital encontram defesa básica no registro escrito na ocasião em que o êrro foi cometido, sem nenhuma preocupação de processo futuro. 


\section{e) Na pesquisa médica:}

1. ${ }^{\circ}$ ) Cada registro, cientificamente perfeito, é mais um bloco de informação disponível para estudo, facilitando aos investigadores chegar a conclusões com maior exatidão e rapidez.

\section{II - CONTEÚdo E FÓRMULA DO REGISTRO MÉdico}

O registro médico é uma história clara, concisa e precisa da vida e da doença do paciente, escrita sob o ponto de vista médico. Por outro lado, estabelece os fatôres que contribuíram para diminuir a resistência e produzir a doença; por outro, chama a atenção para os fatôres que aumentaram a resistência, dando detalhes sôbre esforços malogrados ou não, feitos no passado combater o mal.

Alcança-se o climax na história da presente moléstia, de acôrdo com o paciente e com as observações e o tratamento registrado pelo médico, seus colegas e assistentes.

\section{Seção Médica do Regístro:}

1. $\left.{ }^{\circ}\right)$ Pode ser obtido sòmente sob a supervisão de um médico experimentado; êle não precisa escrevê-lo pessoalmente, mas deve lê-lo e assiná-lo, para cientificar-se de sua exatidão.

2..$^{\circ}$ Deve ser geralmente uma afirmação de fatos. "Negativo" e "normal" são opiniões, e não fatos. A diagnose é uma afirmação de opinião, enquanto que o diagnose final é uma afirmação de opinião amadurecida.

$\left.3 .^{\circ}\right)$ Os formulários usados presentemente podem ser divididos em três classes: a fôlha em branco, o formulário detalhado, e o esbôço. O último é o mais satisfatório.

4. $\left.{ }^{\circ}\right)$ Consiste na história completa do paciente, e inclui o seguinte: Informação identificadora; queixas; história da famílila; história do passado; história da presente doença; exame físico; exames especiais, raios $\mathbf{X}$, laboratório e consultas; diagnóse provisional; tratamento, médico ou cirúrgico; relatório do patologista sôbre tecidos; notas do progresso; condições na alta; diagnóse final; registro do acompanhamento do caso; relatório da autópsia (em caso de morte).

\section{III - ARRANJO DO REGISTRO MÉDICO}

O arranjo do registro médico deve ser definido, para tornar fácil e conveniente a procura de um dado, isto é, as seções devem ser agrupadas como, por exemplo, tôdas as páginas de carta gráfica devem estar juntas, tôdas as ordens para tratamento juntas, e assim por diante, de acôrdo com o tipo.

Como os médicos procuram mais freqüentemente os últimos registros, essas seções devem ser arranjadas em ordem cronológica inversa, pondo-se a última página em cima, nos diversos pavimentos onde se encontram os doentes. 


\section{IV — OBTENÇÃO DO REGISTRO MÉDICO}

Para a obtenção de cada seção do registro médico, algum departamento. da organização do hospital deve ser responsável.

O corpo de enfermeiras é responsável pela seção de enfermeiras.

O médico responsável pela seção médica do registro. Algumas vêzes, pedem-se que internos escrevam o registro médico. De qualquer modo, o médico tem sempre a responsabilidade de ver com que o registro seja feito de modo adequado; deve lê-lo e assiná-lo.

O corpo médico deve apontar um comité de registro médico para avaliar e julgar os registros médicos e apelar para os médicos pessoalmente ou através de relatórios ao corpo médico em geral, a fim de assegurar uma compreensão prática de sua responsabilidade pelos registros médicos.

\section{V - PRESERVAÇÃO DOS REGISTROS MÉDICOS}

Para a preservação dos registros médicos é necessário que se estabeleça no hospital um departamento de registros médicos, comparável em importância com os que são mantidos para outros serviços, e que deve ser localizado, planejado, equipado, encabeçado e organizado ao nível dos outros departamentos do hospital.

a) Escritório dos Registros Médicos:

1. ${ }^{\circ}$ Localizado de modo conveniente a dar acesso aos médicos quando. êstes entram ou saem do hospital.

2..$^{\circ}$ deve ser mobiliado com simplicidade.

$3^{\circ}$ ) Os registros dos pacientes devem ser conservados de maneira a estarem sempre ao alcance, para servir aos fins a que se destinam.

b) Sala de acondicionamento:

$\left.1^{\circ}\right)$ Os registros aqui são apenas ligeiramente menos ativos que aquêles no escritório principal.

2. ${ }^{\circ}$ ) A sala deve ser localizada numa parte acessível do hospital, conveniente para o escritório principal. Deve ser limpo, livre de pó e humidade.

3. ${ }^{\circ}$ A sala deve possuir prateleiras de madeira ou metal, com divisões a cada $60 \mathrm{~cm}$. ou menos, com bastante iluminação entre as divisões.

c) Pessoal:

1. $\left.^{\circ}\right)$ A chefe do departamento deve ser uma bibliotecária de registros: médicos, competente e treinada, responsável pelos registros desde que dêm entrada em seu escritório.

2..$^{\circ}$ Um corpo de auxiliares, bibliotecárias ou estenógrafas pode ser necessário, dependendo isto do tamanho do hospital. 


\section{d) Arquivamento dos registros médicos:}

$1 .^{\circ}$ ) Geralmente, arquivam-se os registros sob o número de admissão, que é o número de identificação do paciente e ao qual se referem todos os indices.

2. ${ }^{\circ}$ ) O sistema centralizado é o mais geralmente usado, com um escritório central para registros médicos, e o número dado ao paciente por ocasião de sua admissão identifíca-o, não importa qual o departamento em que está sendo tratado. Desta maneira, os registros médicos são unificados e contínuos, evita-se repetição, e tôda informação relativa ao paciente fica disponível a todo momento.

e) Indice de Registros:

$1^{\circ}$ ) Dão-se entradas aos registros pelo número ou pela doença, preferindo-se o número. Devem ser também indicados pelo nome do paciente.

$2 .^{\circ}$ ) Os índices de pacientes podem ser conservados separadamente para cada ano, ou podem ser perpétuos - sendo que o índice perpétuo é recomendado para todos os hospitais.

$3^{\circ}$ ) O índice pode ser feito por meio de cartões, com o nome, sendo preferível o sistema de cartão vertical. Cartões de $3 \times 5$ são arquivados alfabèticamente numa gaveta vertical.

$4^{\circ}$ ) Exatidão ao alistar os nomes completos dos pacientes é absolutamente essencial.

\section{VI - USOS DOS REGISTROS MÉdICOS}

Há uma extensiva procura para o uso da informação contida no registro médico, para reestudo, pesquisa, e em cascs médico-legais, casos de seguro e de compensação. O registro deve ser considerado sob dois pontos de vista: - como um documento pessoal e como um documento impessoal. vidual.

a) É um documento pessoal quando é associado com um paciente indi-

b) E' um documento impessoal quando sòmente o seu conteúdo é estudado, sem referências a qualquer indivíduo.

a) Usos do registro médico como um documento pessoal:

$1^{\circ}$ ) Embora o registro seja muito livremente usado no hospital, deve-se sempre ter em mente que, como um documento pessoal, êle é confidencial.

2. ${ }^{\circ}$ ) O estado legal do registro médico como uma comunicação privilegiada, tanto verbal como escrita, varia nos diferentes estados e países. Em alguns estados e países, as côrtes não exigem que os médicos respondam perguntas que divulguem informação obtida como parte do tratamento do paciente. Cada hospital deve consultar o seu próprio advogado.

$\left.3^{\circ}\right)$ O registro médico não pode ser pôsto à disposição de companhias de seguros, juntas de compensação ou organizações semelhantes, exceto com o consentimento escrito do paciente. 
4. ${ }^{\circ}$ ) Executadores de inventário ou representantes legais poderão te1 acesso aos registros no que seja necessário ao cumprimento de seus deveres.

$5^{\circ}$ ) Parentes e amigos do paciente não têm absolutamente nenhum direito de ver o registro médico.

6. $\left.{ }^{\circ}\right)$ Pode ser usado pelo próprio paciente. O paciente requisitá-lo-á pessoalmente ou por escrito. O médico responsável deve ser consultado por uma questão de cortesia.

7. $\left.{ }^{\circ}\right)$ O segundo médico responsável pelo paciente tem direito a ver o registro médico.

b) Usos do registro médico como um documento impessoal:

$1^{\circ}$ ) O primeiro uso como um documento impessoal é a análise mensal de trabalho do hospital. Embora isto se faça primàriamente num relatório formal pelo bibliotecário, o relatório é suplementado por um estudo detalhado dos registros que possam fornecer informações de valor para o levantamento médico.

$\left.2 .^{\circ}\right)$ Seu uso para fins de pesquisa é de natureza puramente científica e daí sua divisão em duas categorias:

a) pesquisa feita por um membro do corpo médico;

b) Pesquisa feita por um médico que não seja membro do corpo médico;

Se a pesquisa é feita pelo membro do corpo médico, não é necessária a permissão do médico que escreveu, a não ser que se pretenda publicá-lo. Se a pesquisa é feita por um médico que não faz parte do corpo médico do hospital, é essencial que se obtenha o consentimento do médico que o escreveu e, geralmente, também, do diretor do hospital."

Como se depreende da transcrição que vem de ser feita, o Dr. MAC EACHERN não aborda sòmente, em sua tese, os registros médicos como documentos de importância básica para o exercício criterioso da profissão: o problema de sua organização, isto é, a posição que devem ter no conjunto da administração a que servem, também não lhe escapou, o que constitui objeto do Capítulo V - Preservação dos Registros Médicos. Para encarecer-lhes o valor recomendado mesmo que se torna necessário para sua preservação o estabelecimento, nos hospitais, de um Departamento de registros médicos, localizado, planejado, equipado e organizado em nível e condições semelhantes às dos outros departamentos do hospital.

Embora a tese do Dr. MAC EACHERN se refira a registros médicos de Hospitais, seus fundamentos são válidos, também, para organizações de menor volume de trabalho; nestas, o Departamento de registro de médicos seria reduzido a um simples arquivo médico central.

Essas considerações são aqui ventiladas porque, ao elaborarmos o anteprojeto para o fichário médico do Ambulatório da Delegacia do D.F., fizemo-lo baseados no sistema MAC EACHERN, cujos resultados já passaram pela prova experimental, nos Estados Unidos, evidenciando sua excelência. 
Norteou-nos, antes de tudo, a idéia de que não haveria necessidade de se perder tempo com outros estudos, quando se poderia aproveitar a experiência magnífica e os conhecimentos de outros povos. O fundamental é que o sistema de arquivo seja bem planejado, eficiente, prático; que não prejudique nenhum serviço e não quebre a continuidade administrativa.

Divulgamos a seguir o ante-projeto por nós elaborado para atender aos reclamos do I.A.P.B.

ANTTE-PROJETO DO ARQUIVO MÉDICO CENTRAL PARA A DELEGACIA DO I. A. P. B. DO DISTRITO FEDERAL

\section{A - Equipamento}

1. $\left.{ }^{\circ}\right)$ Sala ampla, bem iluminada e central;

2..$^{\circ}$ Estantes para 60.000 fichas-pastas numeradas, contendo fichas médicas e resultados de exames;

3. $\left.{ }^{\circ}\right)$ Um chefe médico do Arquivo Médico Central;

4. ${ }^{\circ}$ ) Quatro funcionários do arquivo (dois para de manhã e dois para de tarde), sendo um o responsável pela seção do Arquivo Médico Central;

5. $\left.{ }^{\circ}\right)$ Uma datilógrafa;

6. $)$ Quatro serventes, dois para de manhã e dois para de tarde, para circularem pelas clínicas e serviços da Delegacia do I.A.P.B.;

$\left.7^{\circ}\right)$ Material de escritório.

$$
B \text { - Local e dimensões }
$$

Existe uma sala central, de número 1.419 , na Delegacia do I.A.P.B., ótima para Arquivo Médico Central, no $14 .^{\circ}$ andar do Edifício Darke, medindo mais de dez metros de comprimento, por seis de largura, onde está instalado o Setor de Serviços Médicos. Esta seção precisaria ser deslocada para outro local.

Estima a Seção de Cadastro, em $60 \mathrm{mil}$ associados e beneficiários, atualmente, no Distrito Federal.

As fichas-pastas Mac Eachern costuma pedir, no mínimo, 1,5 centímetros de largura, porque geralmente são presas por grampos de rosca, que engrossam demais os cadernos-fichas. Com êste sistema, teríamos necessidade de 900 metros de estante, para 60.000 pastas.

Cálculo: $60.000 \times 1,50=900$.

Se adotássemos êsse tipo grossíssimo de pasta-ficha, dando-se uma média de 2 cms. de grossura para cada pasta, teríamos em um metro de estante, com oito vãos de prateleiras, altura de dois metros, apenas 400 pastas-fichas, tipo americano.

Cálculos 1 metro de estante: $100 \mathrm{cms} . \div 2=50$ pastas-fichas; 8 metros de estante: $8 \times 50=400$ pastas-fichas. 
Distância das prateleiras, uma das outras: $200 \div 9=22 \mathrm{cms}$.

Se cada metro de estante de 2 metros de altura comporta 400 fichaspastas, precisamos de 150 metros de estantes de 2 metros de altura para 60.000 fichas, o que se tornaria excessivo para a sala em aprêço.

Cálculos $60.000 \div 400=150$ metros de estante de 2 metros de altura.

Lembrou o funcionário Yvon de Araújo Luz, do Setor dos Serviços Médicos, de se adotar a pasta cartolina do I.A.P.B., para ficha-pasta do Arquivo Médico Central, cortada na dimensão das fichas médicas, que seriam empregadas, adotando-se os grampos "De luxe" $80 / \mathrm{P}$. Cada ficha-pasta, por êsse processo fácil e econômico, teria no máximo meio centímetro de espessura. necessitaríamos de 50 metros de estantes, de altura, para 60.000 fichas-pastas. Caberiam folgadamente na sala de estudo.

Cálculo: $150 \div 3=50$.

Dimensões das fichas-pastas: $20 \mathrm{cms}$. de altura por $23 \mathrm{cms}$. de largura.

Dimensões das fichas médicas: $19,5 \mathrm{cms}$. de altura por $22,5 \mathrm{cms}$. de largura.

As fichas médicas, os resultados dos exames de laboratório e raios $\mathrm{X}$, deverão ser empregadas nas fichas-pastas do Arquivo Médico Central. Evitamse, assim, os desperdícios da pluralidade de exames dispendiosos, desnecessários, desordens na rotina e abusos, contribuindo para melhorar o padrão da assistência médica do I.A.P.B.

Sôbre o tipo de ficha médica a ser adotada, diz MAC EACHERN: "Os formulários usados, presentemente, podem ser divididos em três classes: a fôlha em branco, o formulário detalhado e o esbôço. O último é o mais satisfatório". (2)

C - A ficha médica esbôço pode evitar despesas com o fichário índice na Delegacia do I.A.P.B.

Cada ficha esbôço receberia o número da matrícula do associado ou beneficiário; seria uma fôlha de papel de côr, específica para cada clínica, com as dimensões previstas e padronizadas, tamanho $19,5 \times 22,5 \mathrm{cms}$. o que facilitaria a pesquisa no arquivo-pasta; teria no cabeçalho o nome do Instituto, da clínica cu serviço, bem assim a indicação do número da matrícula do associado ou beneficiário.

O fichário índice do Arquivo Médico Central, seria substituído, com vantagem, pela Seção de Cadastro da Delegacia do I.A.P.B.. Os associados novos, que ainda não tivessem número de matrícula, poderiam receber um número provisório, no Cadastro, para o Arquivo Médico Central e que, mais tarde, seria substituído na pasta-ficha, pelo definitivo.

\section{$D$ - Do contrôle das despesas médicas}

clínica ou serviço, bem assim a indicação do número da matrícula do associado destinada ao lançamento das despesas correspondentes às consultas, exames e diversas.

(2) MAC EACHERN, obra citaca. 
O Arquivo Médico Central, nos moldes estudados, possibilitaria o contrôle das despesas efetuadas pelo associado e seus beneficiários, no I.A.P.B., o que, até hoje, não foi efetivamente conseguido. Para isto, tornar-se-ia necessário, conforme sugere o Sr. Natalício Farias, funcionário do Setor de Serviços Médicos, uma Seção de Contrôle dentro do próprio A.M.C., articulada com os diversos setores do Departamento Médico do Instituto dos Bancários.

\section{E - As estantes nos moldes propostos dispensam despesas com arquivos e outras}

Poderiam até ser feitas de madeira pela própria carpintaria do I.A.P.B. e melhor estudadas pelo serviço de engenharia.

Diz Mac Eachern ser mais aconselhavel divisões de 60 centímetros nas estantes. Entretanto, divisões de 30 centímetros de largura, nas estantes para fichas-pastas de $1 / 2$ centímetro de largura, facilitaria a pesquisa.

Os filmes radiográficos, os traçados eletroencefalográficos, as cópias dos laudos médicos e outros podem ser guardados em envelopes, recebendo o número da matrícula dos associados e beneficiários e arquivados em compartimentos por cima das estantes, bem assim os livros do arquivo Médico Central.

Podem ser feitas algumas gavetas nas estantes, para serem guardadas fichas. $\mathrm{O}$ indispensável é que material seja de primeira qualidade.

\section{$F$ - Da rotina}

O associado chegando na Delegacia do I.A.P.B. teria que preencher a seguinte ficha:

$$
\text { ARQUIVO MÉDICO CENTRAL }
$$

Nome do Associado:

(Preencha apenas a parte superior)

Para o beneficiário:

Banco:

Residência:

Telefone:

\section{Cidade:}

Matrícula do I.A.P.B. n. ${ }^{\circ}$ :

Estado:

Caso esteja de passagem, enderêço provisório no Distrito Federal ou Estado do Rio:

Data: / /

ARQUIVO MÉDICO CENTRAL

Ao Serviço de:

Matrícula n. ${ }^{\circ}$ :

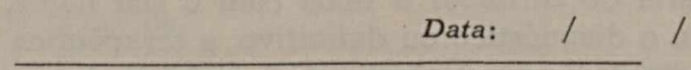

Rubrica do funcionário 
O funcionário do Arquivo Médico Central preencheria a parte inferior, entregando-a ao associado que se encaminharia à clínica.

A parte superior seria devidamente investigada e depois fichada em uma gaveta-arquivo. Também deverá ser registrado o pedido do associado ou beneficiário, no Livro Diário:

INSTITUTO DE APOSENTADORIA E PENSÕES DOS BANCÁRIOS ARQUIVO MÉDICO CENTRAL

\begin{tabular}{|c|c|c|c|}
\hline $\begin{array}{l}\text { Matrí́cula No } \\
\text { I.A.P.B. }\end{array}$ & $\begin{array}{l}\text { ENCAMINHADO } \\
\text { i CLÍNICA }\end{array}$ & $\begin{array}{c}\text { VOLTA DA FICHA } \\
\text { AO ARQUIVo } \\
\text { (data) }\end{array}$ & OBSERVAÇÕES \\
\hline & & & \\
\hline & & & \\
\hline & & & \\
\hline & & & \\
\hline & & & \\
\hline
\end{tabular}

O Serviço do Arquivo Médico Central colocaria a ficha de associado retirada da estante, em um envelope e a encaminharia diretamente ao médico, por intermédio do seu servente circulante. A atendente assinaria a recepção da ficha.

\section{$G-O$ envelope de circulação}

Medindo 25 centímetros de largura por 20,5 de altura, deve ser resistente.

Para garantia do sigílo profissional da ficha-pasta, quando em circulação, o fêcho do envelope deve penetrar em uma alça e possuir em sua extremidade um orifício, contendo um ilhôs, no qual será introduzido um cordel.

Haverá no corpo do envelope uma matriz de papelão à qual deverá ser prêso o cordel, por intermédio do sêlo de segurança, na ocasião em que fôr fechado.

\section{$H-D o$ atendimento pelo médico}

O médico teria de carimbar a ficha com o seu nome, dataria, escreveria a anamnése, daria o diagnóstico ou definitivo, a terapêutica e assinaria a ficha, colocando-a novamente no envelope para mais tarde o servente circulante apanhá-la e levá-la de volta ao Arquivo Médico Central. 
$I$ - Quando o médico pede exames de laboratório e raios $X$

Teria de carimbar a ficha com o seu nome na fôlha do laboratório ou Raios X, fazendo os pedidos. Forneceria ao associado uma guia apenas com c número da matrícula e os exames pedidos, assinando-a. $\mathrm{O}$ associado com esta guia poderia fazer seus exames.

O Arquivo Médico Central providenciaria, em face dos pedidos registrados, a descida das fichas-pastas para o Laboratório ou Raios X, para os competentes registros no Laboratório ou Raios X, sendo depois tudo devolvido, inclusive radiografias, ao Arquivo Médico Central, por intermédio do servente circulante, para que tudo fique devidamente arquivado.

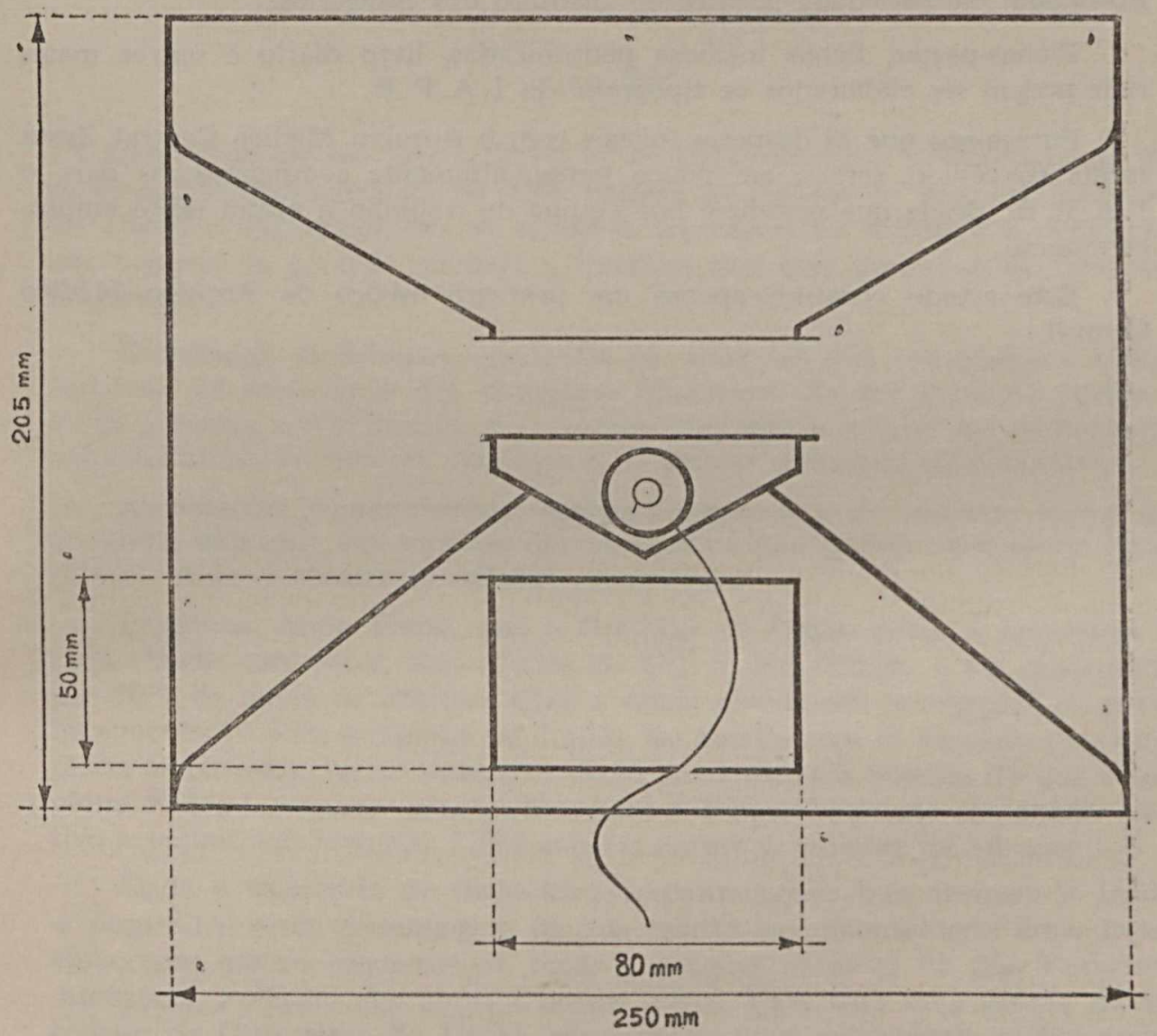

J - Da comunicação entre as Clínicas e o Arquivo Médico Central

Existe em tôdas as salas, na Delegacia do I.A.P.B., rêde interna de. telefones, com números próprios.

Cada clínica ou serviço tomaria o número de seu telefone. O A.M.C. teria um quadro de chamadas, semelhante ao dos grandes hospitais, que ilumi- 
naria o número da clínica, ou serviço quando o médico, em seu consultório, tocasse a campainha. O funcionário do arquivo, pelo número da chamada, que seria o da sala e do telefone, entraria imediatamente em ligação com o médico. O servente circulante levaria, no mesmo instante, o material pedido, garantindo, dêsse modo, a rápida comunicação entre as clínicas e o Arquivo Médico Central.

\section{$K-$ Regulamento}

O Arquivo Médico Central deve possuir um regulamento própr-o, conforme preconisa MAC EACHERN e ser supervisionado por um Consclho Médico e Administrativo do I.A.P.B. Parece-nos que neste Conselho, devem tomar parte os Diretores Médicos, o Chefe Médico da Delegacia do I.A.P.B. e o Presidente da Sociedade Médica do Instituto dos Bancários.

Fichas-pastas, fichas médicas padronizadas, livro diário e outros materiais podem ser elaborados na tipografia do I.A.P.B.

Parece-nos que as despesas iniciais com o Arquivo Médico Central, desta forma concebido, seriam em pouco tempo altamente compensadoras para o I.A.P.B. desde que possuísse boa equipe de trabalho a altura dêste empreendimento. Central.

Este estudo constitui apenas um primeiro esbôço de Arquivo Médico 